\title{
Defeating pragmatic encroachment?
}

\author{
Matthew McGrath ${ }^{1,2}$
}

Received: 13 February 2016 / Accepted: 1 November 2016 / Published online: 15 November 2016 (C) The Author(s) 2016. This article is published with open access at Springerlink.com

\begin{abstract}
This paper examines the prospects of a prima facie attractive response to Fantl and McGrath's argument for pragmatic encroachment. The response concedes that if one knows a proposition to be true then that proposition is warranted enough for one to have it as a reason for action. But it denies pragmatic encroachment, insofar as it denies that whether one knows a proposition to be true can vary with the practical stakes, holding fixed strength of warrant. This paper explores two ways to allow knowledge-reason links without pragmatic encroachment, both of which appeal to defeat. The first appeals to defeaters of reasons. If you know the bank is open tomorrow, what you know is available as a reason, but it may be defeated by considerations concerning the stakes. The second appeals to defeaters which do not defeat reasons but which nonetheless do something similar: they make the action recommended by those reasons vicious. In a high stakes case performing the "risky" action would be vicious even if it is justified in the sense of being supported by undefeated reasons. What is defeated is a virtue-based epistemic status rather than reasons or justification. I argue that neither proposal halts the march from a knowledge-reason link to pragmatic encroachment.
\end{abstract}

Keywords Defeaters · Knowledge - Pragmatic encroachment · Practical reasons · Exclusionary reasons $\cdot$ Epistemic virtue $\cdot$ Joseph Raz $\cdot$ Maria Lasonen-Aarnio

In contemporary epistemology, pragmatic encroachment is the thesis that whether one knows a proposition can vary with pragmatic factors, such as the practical stakes,

\footnotetext{
Matthew McGrath

mcgrathma@missouri.edu

1 University of Missouri, Columbia, MO, USA

2 Arché Philosophical Institute, University of St. Andrew, St Andrews, UK
} 
holding fixed the strength of one's warrant with respect to the proposition. ${ }^{1}$ Consider the train cases from Fantl and McGrath (2002). Start with a low stakes case, in which you merely want to get to Providence by train from Boston, so that nothing much turns on whether the train rolling into the station is the express train going nonstop from Boston to Providence or the much slower local train which makes stops at numerous stations along the way, including Foxboro. You overhear someone saying that the train now entering the station is a local. In such a case, one might think, testimony from a stranger is enough to know the train is a local. But now vary the case. Suppose your career was on the line. Suppose you had to arrive in Foxboro by a certain time and that only the local train services Foxboro. In this revised case one might think the testimony of a stranger isn't good enough for you to know it is a local. You need to do more checking. (We suppose there is time to check.) If these suggested verdicts are correct, then you know the train is a local in the low stakes train case but don't know in the high stakes train case, despite your warrant for the train is a local being the same in the two cases.

Although intuitions about cases like these provide some support for the thesis of pragmatic encroachment, one might reasonably demand better evidence before accepting such a surprising view. In past work, Jeremy Fantl and I have tried to provide a stronger basis, as have other "encroachers." We have attempted to find an account which makes sense of the intuitions and explains them as stemming from general principles. ${ }^{2}$ In our view, pragmatic encroachment isn't merely a curiosity about particular cases; it is a consequence of an important connection between knowledge and reasons for action, namely that when one knows $\mathrm{p}, \mathrm{p}$ is epistemically qualifiedwarranted enough - to be a reason one has for action. In a low stakes case, a proposition might be warranted enough to be among one's practical reasons, whereas in suitably chosen high stakes case the same degree of warrant might be insufficient.

A note about terminology: I use ' $p$ is warranted enough to be a reason you have' to state that whatever shortcomings there might be in the degree of warrant $p$ has for you do not disqualify $\mathrm{p}$ from being a reason you have (and mutatis mutandis for being warranted enough to justify). In some cases, a proposition might have some warrant for a person but not enough warrant to be among the person's reasons. If I have some weak ground for believing that it will rain next Thursday, then it will rain next Thursday will not be warranted enough to be among my reasons for doing or believing things. I would need stronger warrant for this proposition to be among my practical and theoretical reasons.

If there is such a knowledge-reason connection, we can see why knowing is an important epistemic achievement, beyond merely having a true belief with a certain degree of warrant. Knowing that $\mathrm{p}$, unlike merely having true belief with a certain degree of warrant for $\mathrm{p}$, guarantees that $\mathrm{p}$ is warranted enough to be among one's

\footnotetext{
1 In this paper, I don't delve into detail about exactly which pragmatic factors matter. I write as if it is "the stakes." However, to consider the matter properly, one would need to consider other candidates, such as odds. Here I will put aside this issues, as important as they are. They do not matter to the key questions of this paper, as far as I can see. For an argument that odds are the epistemically relevant pragmatic factor, see Weatherson (2011).

2 See in addition to Fantl and McGrath (2009), Hawthorne (2004), Stanley (2005), and Weatherson (2011, 2012).
} 
reasons for action. Reasons for action matter, and knowledge matters at least in part because it makes a proposition warranted enough to be among one's reasons for action.

Seeing the attractions of this picture of knowledge and its relation to practical reasons, one might hope to find a way to embrace it without also embracing the admittedly unattractive thesis of pragmatic encroachment. ${ }^{3}$ This paper asks whether we can have our cake and eat it, too.

The question of this paper, thus, is whether and how it is possible to resist arguments from principles asserting a knowledge-reason link to pragmatic encroachment. I limit myself to the following argument, one due to Jeremy Fantl and myself. (Fantl and McGrath 2009, 2012), where ' $\phi$ ' ranges over actions as well as beliefs:

1. If you know $p, p$ is warranted enough to be a reason you have to $\phi$. (This is the knowledge-reasons link, which I dub 'KR')

2. If $\mathrm{p}$ is warranted enough to be a reason you have to $\phi, \mathrm{p}$ is warranted enough to justify you in $\phi$-ing.

3. So, if you know $\mathrm{p}, \mathrm{p}$ is warranted enough to justify you in $\phi$-ing. (This is the knowledge-justification link, dubbed ' $\mathbf{K J}$ ')

4. Whether $\mathrm{p}$ is warranted enough to justify you in $\phi$-ing can vary between a low stakes case in which you know that $\mathrm{p}$ and an appropriately chosen high stakes case, holding fixed your warrant for $\mathrm{p}$ across the cases.

5. So, whether you know p can vary with the stakes, holding fixed your warrant for p. (This is the thesis of pragmatic encroachment).

Here and throughout I use 'p justifies you in $\phi$-ing' to express the strong claim that $\mathrm{p}$ is a reason you have in virtue of which you are justified in $\phi$-ing-i.e., in virtue of which $\phi$-ing is permissible for you. Thus, to say that the train is a local justifies you in boarding is to say that it is a reason you have in virtue of which you are justified in boarding.

One final note before proceeding. For the sake of simplicity, I will write as if the generalization (4) stands or falls with the train cases differ in respect of in whether it's a local justifies one in boarding the train. Thus, I will approach the question of whether we can resist the argument (1)-(5) by considering whether we can block the instance of this argument that comes from taking it's a local as the substitutends for 'p'.

In our (2009), Fantl and I argued that there is no way to resist the march from KR to pragmatic encroachment. But we considered in detail only one way of halting the march, namely appealing to overriding defeaters to deny (2). We considered the possibility that in a high stakes case, such as their high stakes train case, one has two reasons - a reason for boarding without delaying and a reason for checking further, where the latter overrides or outweighs the former. (I use 'override' and 'outweigh' as synonyms.) The former reason, the reason for boarding, is that the train is a local and gets me to my destination in time. For short, let us formulate this reason as "the train is a local." The reason for checking further, rather the boarding, is that there is a serious risk of very bad consequences if one boards right away and no comparative

\footnotetext{
3 Among philosophers who explicitly pursue this line are Anderson (2015) and Cohen (2012). For my response to Cohen, see Fantl and McGrath (2012).
} 
serious risk of very bad consequences if one checks further first and then revisits the matter. Let us formulate this second reason as "there is a serious risk the train isn't a local." We argued for two claims: (i) if one could have both of these reasons at once, it is by no means clear that the reason for checking further-there being a serious risk the train isn't a local—would override the reason for boarding — that the train is a local; (ii) one can't have both reasons at once. Our argument for (ii) was based on the premise that if one could have both reasons at once it ought to be sensible to weigh them against one another-asking which is more important, the fact that the train is a local and gets me to my destination or the fact that there is a serious risk that it is not a local-whereas in fact such weighings are not sensible.

However, I now think these arguments do not settle the matter. For, even if there is no overrider that defeats the reason for boarding in high stakes cases, there might be another sort of defeater that does. The literature on reasons suggests that defeat isn't always a matter of overriding. One goal of this paper is to determine whether some other form of defeater might turn the trick better than overriders. If so, we could block the argument (1)-(5) at step (2), holding onto the knowledge-reason connection without giving in to pragmatic encroachment. We would embrace KR (step 1) but not $\mathrm{KJ}$ (step 3).

This paper also has a second related goal: to examine the prospects for claiming that, while steps (1)-(3) are acceptable, step (4) is not. On this line, if the train is a local is warranted enough to justify you in boarding in a low stakes case, it would remain warranted enough to justify you in boarding no matter how high the stakes. How could this be? Recent work by Maria Lasonen-Aarnio (2010) on "unreasonable knowledge," suggests a way one we might explain how. Yes, even in the high stakes train case the fact that the train is a local does still justify you in boarding without checking further, just as it does in the low stakes case. But although it justifies you in boarding, you wouldn't be reasonable — or better, virtuous - to board if the stakes were too high. ${ }^{4}$ Being justified in an action is one thing; the action being a virtuous one is quite another. Rejecting (4) on such grounds is consistent with accepting (1)-(3), and so with accepting both KR and KJ. Thus, we have the tantalizing prospect of having and eating our cake.

I will argue that the prospects are dim for both of these proposals: there is no plausible story about defeaters which enables us to embrace KR without KJ and there is no good reason to think that a virtue-based approach will enable us to embrace $\mathrm{KR}$ and $\mathrm{KJ}$ but not pragmatic encroachment. In a final section, I consider whether, attractive as it may initially seem, KR (i.e., (1)) ought to be abandoned. I point out the implausible consequences of doing so. My conclusion is not that the argument (1)-(5) is sound, but that we so far lack a plausible account of where and how it could fail. If I am right, we lack a way to halt the march from the claim that knowledge provides reasons for action to pragmatic encroachment. We may well not be able to both have and eat our cake.

\footnotetext{
4 Lasonen-Aarnio does not explicitly identify her view on unreasonable knowledge with a virtue-based approach, saying only that it "comes close."
} 


\section{The search for the right sort of defeater}

To block the argument at step (2), we want a defeater that meets certain conditions:

(a) It exists in the high stakes case but not in the corresponding low stakes case.

(b) It wouldn't exist if your warrant were suitably stronger in the high-stakes case.

(c) The existence of the defeater does not render the target proposition-e.g., the train is a local-insufficiently warranted to be a reason you have not to do the relevant action (e.g., board the train).

We want a defeater meeting condition (a) because we want to allow that the target proposition can indeed be a justifying reason you have in a low stakes case. The train is a local in a low stakes case can justify you in boarding it. We want a defeater meeting condition (b) because the subject with absolutely certain knowledge that the train is a local is justified in taking the train, and so the defeater mustn't exist there. (Thus, the mere fact that one would suffer bad consequences of the relevant action if the target proposition is false will not give us the defeater we want.) Finally, we want a defeater meeting condition (c) because we want to retain the knowledge-reasons link KR. If the defeater disqualified the target proposition from being among your practical reasons, due in part to insufficient warrant of the proposition, this would undermine KR. KR requires that in the high stakes case the target proposition is warranted enough to be a reason you have for the action. There is a serious risk that the train isn't a local meets these conditions. As far as the identity of the defeater is concerned, this one-or one very similar to it-is what we want.

But this is the easy part. We know what roughly the defeater must be. The hard part is to explain how this defeater defeats the reason for boarding the train, i.e., that it is a local train. Presumably, we do not want to invent a wholly new kind of defeat to suit our purposes. The explanatory value of this invention would be questionable. Much better to show how the defeater's mode of defeat is a familiar one, found not merely in high stakes cases.

Recent work on reasons and defeaters suggests that there are at least the following types of defeaters of practical reasons:

- Overriders - these defeat by outweighing

- Cancelers - these defeat by depriving the defeated consideration of being a reason at all

- Attenuators - these defeat by reducing the strength of the reason, so that it is then outweighed by some other reason that wouldn't normally outweigh it.

- Exclusionary reasons - these defeat by excluding others reasons where exclusion neither cancels, attenuates nor outweighs them.

We have already discussed the case of overriders. Let us consider defeaters of the other three categories.

Consider the following example of a canceler from Raz (1999, pp. 27-28). I promised you that I would return your book. You later call me up to say you've released me from the promise-you don't need the book back. This defeats my promise as a reason to return the book. But it doesn't leave the force of the promise intact and simply outweigh it. It renders the fact that I promised no longer any reason to return 
the book. This has characteristic implications. There need be no basis for regret if I don't return the book, unlike another sort of case in which I don't return the book because I give it to someone who uses it for some good purpose. And should I receive further reasons to return it, the promise does not combine with these reasons to give me a greater reason. ${ }^{5}$

Consider the following example of an attenuator from Jonathan Dancy (2004, pp. 41-42). That a person I know is in dire straits and needs money is a reason to provide him assistance. But suppose I learn that his predicament is all his fault (he knowingly brought it on himself). This seems to reduce the strength of that reason. That he is in dire straits is not as powerful a reason for me to provide him assistance as it was prior to my acquiring the defeater. Given its weaker strength, it is now more easily outweighed. Still, the defeated reason remains some basis for regret if I do not help him, and it can combine with other reasons to comprise a stronger case for providing him assistance.

Excluders are not as straightforward as overriders, cancelers or attenuators. Like overriders, they neither deprive a consideration from being a reason nor reduce its strength, but, like cancelers, they deprive the reason of an important role that generally accompanies being a reason. Just what this role is isn't obvious. I will consider several examples from Joseph Raz, who introduced the notion of an exclusionary reason.

Raz (1999, pp. 37-39) gives three leading examples: Ann, Jeremy and Colin. Ann has been offered a financial deal, an offer which is to expire in the next few hours. She has heard the relevant considerations, but they are complicated, and she is tired. She sees her situation this way: she can't reasonably make a decision in this situation, for her judgment is compromised. She declines the offer, but not because of the intrinsic reasons against it, but rather because she thinks she should not decide on the merits of the case, given her exhaustion. Jeremy is an officer commanded by a superior to appropriate a van. He sees better ways to achieve the same military objectives than by appropriating the van and thereby causing this hardship to its owner. But he thinks it is not for him to decide on the merits. That is a privilege only his superiors enjoy. Finally, Colin has promised his wife not to let considerations other than his son's interests bear on his decisions concerning his son's education. He could send the son to a state-supported school, which would serve his own interests well and his son's nearly as well, but on the basis of his promise, he excludes this consideration and sends his son to a more expensive and slightly superior private school.

Raz aims to describe the way the protagonists in the examples see their situation. Ann doesn't think her tiredness is a reason that outweighs the positive reasons for taking the financial deal. Rather, she sees it as a reason not to act on the merits of the case-not to act on such reasons. Jeremy does see the command as a reason to appropriate the van, but on the merits, it seems appropriating the van isn't the best thing to do, and yet because he has been given the command, he thinks he must not act on the particular merits of the case. Again, the command is a reason not to act on certain reasons. Finally, Colin thinks that on the merits of the case, sending his son to a state-supported school would indeed be best all around. However, he sees his promise

5 Dancy's (2004, pp. 38-41) disenablers are cancelers. The term 'canceler' is taken from Raz's (1999, p. 27) terminology of "cancelling conditions." 
as giving him a reason not to act on any reasons concerning his own interests when making decisions about his son's education.

According to Raz, then, exclusionary reasons are reasons not to act on certain reasons. They do not-qua exclusionary reasons - affect the balance of reasons for and against the action. (He does allow that there are exclusionary reasons which are themselves also first-order reasons, as in Jeremy's case, but their exclusionary function has nothing to do with their being first-order reasons.)

Here is a table of the defeater types, distinguished by their effects on the considerations defeated:

Effects on the defeated consideration

\begin{tabular}{lll}
\hline & $\begin{array}{l}\text { Allows it to remain } \\
\text { a reason with the } \\
\text { same strength }\end{array}$ & $\begin{array}{l}\text { Allows it to func- } \\
\text { tion in the way rea- } \\
\text { sons usually do }\end{array}$ \\
\hline Overriders & $\mathrm{Y}$ & $\mathrm{Y}$ \\
Cancelers & $\mathrm{N}$ & $\mathrm{N}$ \\
Attenuators & $\mathrm{N}$ & $\mathrm{Y}$ \\
Excluders & $\mathrm{Y}$ & $\mathrm{N}$ \\
\hline
\end{tabular}

I now consider whether any of these candidates of defeater might suit the purposes of someone wanting to reject the argument from KR to pragmatic encroachment at step (2). We've considered overriders, and now we turn to the others.

The trouble with cancelers is that they run afoul of KR. If there is a serious risk that the train isn't a local cancels the train is a local as a reason to board it, then it's partly due to weaknesses in the warrant of the latter that the defeater cancels it as a reason. But this is just to say that the train is a local isn't warranted enough to be a reason on has to board. And unless one is going to accept pragmatic encroachment and claim that in the high stakes train case one doesn't know the train is a local, saying that the train is a local isn't warranted enough to be among one's reasons to board commits one to denying KR. So, we put aside cancelers.

One can retain KR by appealing to attenuators. However, the hypothesis of attenuation is implausible. Assuming it is a reason in the high-stakes case, is the train is a local (and gets me to my destination without a hitch) any less of a reason in this case than it is in the low stakes case? It doesn't seem so. If it is a reason one has, it seems exactly as powerful a reason in both cases. Compare Dancy's example. Someone's being in dire straits is perhaps a strong reason to help him financially. That the person's troubled situation is all his own responsibility attenuates this reason. It doesn't cancel it, but it weakens its force. That the train is a local and gets me to my destination without a hitch, however, doesn't become only a minor point in favor of boarding if the stakes are high: it is still a major point of boarding. If one doesn't take the train, one may well regret it once given more complete information: "ah, I should have taken it; I needn't have bothered with the extra inquiry!" The regret is not less than the regret in a low stakes case. By contrast, there is reduced regret across Dancy's two cases.

Although exclusionary reasons work in somewhat mysterious ways, they might seem exactly what someone wanting to accept KR without accepting KJ needs. Intu- 
itively, it might well seem that if you do know in a high stakes case, you ought to bracket or exclude this knowledge in decision-making. But how is such bracketing to be understood?

Consider Jeremy in Raz's example. Why isn't he justified in refusing to appropriate the van? He has extremely strong reasons that are not canceled, attenuated or outweighed. How can a reason not to act on those reasons make him unjustified in refusing to appropriate the van? I cannot see how to answer these questions. If one has a reason that isn't canceled or outweighed and is extremely strong, then one has conclusive reason to do the act and so one is justified to perform the act. Reasons not to act for certain reasons do not seem to affect this.

However, there is an alternative and better interpretation of the workings of exclusionary reasons: exclusionary reasons do not affect what one is justified in doing; rather, they affect what one can justifiably do on the basis of certain reasons. This interpretation fits with Raz's (1999, p. 41) remarks about the phenomenology of cases in which the excluded reasons to $\phi$ are stronger than the reasons not to $\phi$. He claims that we experience a "peculiar feeling of unease," associated with two perspectives we occupy when evaluating an action. Consider the case of an action made on the basis of excluded reasons, where, let us suppose for simplicity that all the reasons supporting that action are excluded. On the one hand, your action was supported by the balance of reasons, and deserves positive evaluation because it is justified; and yet in performing the action on the basis of those reasons, you failed to conform to a reason, namely the reason not to act on those reasons.

If our interpretation of exclusionary reasons is correct, appealing to exclusionary reasons cannot help block the argument from KR to pragmatic encroachment at step (2). Exclusionary reasons do not stand in the way of excluded reasons justifying actions. Thus, KJ (i.e., (3)) is not denied. What is denied is step (4). In the high stakes case, you remain justified in boarding the train, and what justifies you in boarding the train is the fact that it's a local. It's just that, unlike in the low stakes case, in this case you have a reason not to act on this reason. So, you are justified in boarding the train in virtue of having this justifying reason, but you cannot justifiably board for that reason.

It's a clever proposal, but problematic for two reasons. First, think about what it takes to deny (4) if one accepts KJ. Here again is (4):

(4) Whether $p$ is warranted enough to justify you in $\phi$-ing can vary between a low stakes case in which you know that $\mathrm{p}$ and a high stakes case, holding fixed your warrant for $\mathrm{p}$ across the cases.

On a plausible version of fallibilism about knowledge, one can know that $\mathrm{p}$ in a low stakes case even though there is still some epistemic risk for one that not-p. The low stakes train case is presumably such a case. By KJ, the fact that it's a local is warranted enough to justify you in boarding in the low stakes train case. Indeed, it does justify you in boarding. To deny (4) one must think that if you start out in a low stakes train case, then no matter how high the stakes rise, holding your warrant for the fact that it's a local fixed, you will remain justified in boarding the train (rather than playing it safe 
by checking further). ${ }^{6}$ But it seems that if there is some risk that the train isn't a local in the low stakes train case, then in some suitable high stakes case this same small risk can make a difference to whether you are justified in boarding or instead justified in checking further. It is a staple of decision theory that small risks can matter to what one is justified in doing depending on the shape of the outcome matrix. It seems a high price to give up this principle to resist the argument for pragmatic encroachment.

The second reason to be unhappy with the appeal to exclusionary reasons is that it predicts certain absurd thoughts ought to be sensible. Let's start with Jeremy's case. Jeremy can sensibly think:

Appropriating the van would cause hardship to the owner and is not necessary to achieve the immediate military goals. That's a reason for me not to appropriate the van. Indeed, it is a conclusive reason for me not to appropriate it. But I can't act for that reason. I have been commanded by my superior to appropriate it. So I cannot do what I have conclusive reason to do.

But can the protagonist in the high stakes train case sensibly think the following?

It's a local and gets me there in short order. Yes, that's a reason. Indeed, it is a conclusive reason to board it. But I can't act for that reason because the stakes are just too high and there's a chance I'm wrong. So I cannot do what I have conclusive reason to do.

The two cases seem markedly different. In the high stakes train case it seems the only sensible thing to do is to back off somewhat from the claim about conclusive reasons to board-rather than to embrace it but insist that one cannot act for such reasons.

\section{A virtue-based account?}

We now turn to a second attempt to block the argument from KR to pragmatic encroachment, one that, like the exclusionary reason gambit, aims to block it at step (4), conceding KJ. As we will see, this account, too, appeals to defeaters, but not defeaters of reasons or justification. The account I will examine is inspired by ideas of Maria Lasonen-Aarnio, although it is not endorsed by her. I begin with the ideas from Lasonen-Aarnio.

On plausible theories of knowledge, e.g., safety views, Lasonen-Aarnio notes, knowledge doesn't seem to be compromised in stock "defeat cases." To use the stock example, your belief that a particular object is red, based on perception, remains safe even if you dismiss a piece of misleading evidence that the lighting conditions are abnormal. You have a so-called "defeater," but you retain the knowledge, if such

\footnotetext{
6 The only other option would be to concede that there is a high stakes case in which you aren't justified in boarding, and so in which it's a local fails to justify you in boarding, but to insist that it's a local in this case would still be warranted enough to justify you in boarding. (This is an option suggested by Weatherson on his blog Thoughts, Arguments and Rants (March 31, 2010.) But it's a local in this high stakes case would fail to justify you in boarding in part because you lack strong enough warrant. So, to deny (4) on this option would be to abandon KJ. But on the exclusionary reasons account, as we are interpreting it, KJ is maintained.
} 
theories of knowledge are correct. Still, it seems traditional epistemologists who take knowledge to be lost in such cases are right about one thing: if you maintain your belief in the face of the misleading evidence about lighting conditions, you are criticizable in some sense. Your knowledgeable belief is, as Lasonen-Aarnio says, unreasonable.

Lasonen-Aarnio mentions the possibility of extending such claims to other normative statuses. Extended to justification, the idea would be-again, to use the stock example - that if you acquired your belief that a particular object is red through wellfunctioning perception, your belief remains justified even if you dismiss misleading evidence that the lighting is abnormal. As with unreasonable knowledge, we might speak of unreasonable justified belief. We might also extend Lasonen-Aarnio's ideas to reasons for belief. Suppose perception affords you a reason to believe an object is red, a reason which makes you justified in believing the object is red. Suppose you next acquire misleading evidence that the lighting is abnormal. The thought would be that you retain the justifying reason-you still have that reason and it still justifies you in the belief-but it would be unreasonable for you to believe that the object is red. Finally, and most applicable to our own topic, one might extend the ideas to reasons for action. A person's reason to perform a certain action might survive the acquisition of a seeming defeater: you might have a reason to perform a certain action, and the reason might justify you in performing the action, despite the fact that you wouldn't be reasonable to perform it due to your possessing some other piece of information.

How can we make sense of this notion of reasonableness? Building on LasonenAarnio's discussion, we can offer the following account. We are not perfect detectors of justifying reasons. In some cases, because of our limited epistemic capacities, considerations that are not in fact justifying reasons will seem to be justifying reasons, and in other cases, considerations that are justifying reasons will seem not to be justifying reasons. Such cases are inevitable. As theoreticians, we shouldn't react to these cases by identifying justifying reasons with what seem to be justifying reasons. Rather, we should distinguish two related but distinct modes of evaluation. We can evaluate an action or belief as justified or not according to the reasons a person has, and we can evaluate an action as reasonable or not according to what someone with good but humanly feasible habits would do. Importantly, what counts as reasonable belief and action will depend on which habits, among those that are feasible, result across normal cases in the best promotion of the sorts of reasons at issue. In the face of misleading counterevidence, the reasonable doxastic response is to give up one's belief or reduce confidence. One who has this habit will achieve knowledge more reliably over a range of normal cases than one who doesn't. Thus, in the face of misleading counterevidence, the reasonable thing to do is suspend belief, even though the reasons against which the counterevidence speaks do justify one in believing that $\mathrm{p}$. What we have been referring to as "misleading counterevidence" and "defeaters of justification" strictly speaking does not cancel or reduce in any way one's support from reasons. These considerations, then, do not defeat justification. They defeat reasonableness.

Let's apply this set of ideas to our cases. ${ }^{7}$ Rather than using the term 'reasonable', I use 'virtuous'. 'Reasonable', in our ordinary practices of evaluation, is too closely

7 John Hawthorne suggested a possibility like this to me (p.c.). 
tied to 'justified'. The claim will be that, in the high stakes case, the virtuous person will check further about whether the train is a local or express, despite having it's a local as a justifying reason to board without delay. Human beings with such habits will generally fare better overall than human beings with habits that would lead them to board without delay in the high stakes train case. We can think of information about the stakes as playing the same role for action that the misleading counterevidence allegedly plays for belief: they defeat virtuousness, not justification. ${ }^{8}$

What should we say about virtuous belief in the high stakes cases? Will a virtuous person in the high stakes train case believe it is a local? If we answer negatively, we would be embracing a kind of pragmatic encroachment, not about knowledge but about virtuous belief. Now, one might think that this is a case of apples and oranges: ${ }^{9}$ pragmatic encroachment about virtuous belief is one thing, pragmatic encroachment about knowledge is something quite different. However, leeching is hard to avoid. We have understood virtuous belief along the lines of Lasonen-Aarnio's particular account of reasonable belief, which she explains in terms of habits or dispositions conducive to knowledge. But if knowledge isn't stakes-sensitive, it is hard to see how it could be virtuous to believe in the low stakes train case but not in the high stakes one. If I have the habit of believing in both such cases, I will better achieve knowledge generally, since knowledge (we're assuming) isn't stakes-sensitive. Moreover, it is not clear why ignoring the stakes in one's beliefs is infeasible. If virtuous belief is understood in terms of manifesting knowledge-conductive habits, then if knowledge isn't stakes-sensitive, then neither, it seems, is virtuous belief.

If one finds the virtue-based approach attractive but substitutes justified belief for knowledge as what virtuous habits tend to best produce, similar reasoning will suggest that unless one wants to accept pragmatic encroachment about justified belief, one shouldn't accept it for virtuous belief. But it is difficult to see how one could accept pragmatic encroachment about justified belief without accepting it for knowledge. One would have two divergent notions of virtuous belief to contend with, one targeting the promotion of knowledge, which on the view under consideration isn't stakes-sensitive, and the other targeting the promotion of justified belief, which on this view is stakessensitive. In the high stakes train case, it would be virtuous in one epistemically relevant sense to believe the train is a local but vicious in another. Perhaps if one thought knowledge and justified belief were quite different matters one could live with the resulting framework. But anyone who thinks knowledge requires justified belief will find the framework unacceptable. Moreover, even philosophers who think knowledge is possible without justified belief should be troubled by the framework. For, there are cases in which, given the way one has formed one's belief, one knows only if one has good reasons, and in such a case it is hard to see how knowledge could be present without justified belief. The train cases seem to be examples.

The proponent of the virtue response to our argument from KR to pragmatic encroachment about knowledge, I conclude, would arrive at a theoretically more

\footnotetext{
8 An interesting question, not pursued here, is whether the apparatus of exclusionary defeaters, understood as second-order reasons not to act on or believe on the basis of certain classes of first-order reasons, provides all the necessary resources for a virtue-based theory of the kind under consideration.

9 Thanks to two referees for raising this objection.
} 
defensible position if she denied that virtuous belief is susceptible to pragmatic encroachment.

Note a peculiarity about the resulting picture. When it comes to the epistemic standards for a proposition's being sufficiently warranted to be a justifying reason a person has, the account treats knowledge as the correct (or at least $a$ correct) standard for both practical and theoretical reasons. However, when it comes to virtuous action and belief, knowledge isn't good enough for both virtuous action and virtuous beliefonly for virtuous belief, not for virtuous action. In the high stakes train case, one's warrant for the train is a local isn't strong enough to make boarding the train virtuous but $i s$ strong enough to make it virtuous to believe the train is a local and to believe other propositions supported by the train is a local. Why the asymmetry?

One might defend the asymmetry by appealing to the fact that for action but not belief, the outcomes can vary dramatically in their value and disvalue across states of the world and that since the disvalue can be so great, a virtuous person in certain choice situations will require stronger warrant for $\mathrm{p}$ before acting on $\mathrm{p}$ than she requires to believe on the basis of $\mathrm{p}$. But I cannot see why these same considerations wouldn't show as well that it takes more epistemically to have $\mathrm{p}$ as a practical reason in high stakes situations than it does to have $\mathrm{p}$ a theoretical reason in those same situations. But this would be to give up KR, because one would be claiming that knowledge is not epistemically enough to have $\mathrm{p}$ as a practical reason in high stakes situations.

Finally, notice that, just as we saw for the exclusionary reasons account, the virtue account, or at least the versions of it that abjure pragmatic encroachment about virtuous belief, predicts that the virtuous person who thinks carefully about her situation in the high stakes train case could sensibly think thoughts that seem absurd:

the train is a local and gets me to my destination; thus, I do better to board it immediately rather than inquiring further; and yet I'm going to inquire further;

I'm going to do what will have worse results.

In a high stakes case, one feels an urge to temper the final line: I am going to do what very likely will have worse results. One feels a need to hedge throughout-the train is a local (surely?) and I (surely?) do better to board it immediately. One recoils from embracing the final line outright: to embrace it is to embrace something seemingly absurd.

I don't claim that the fact that the virtue-based account would have the virtuous person thinking such alien and absurd thoughts seals the deal against it. But it is a cost that must be acknowledged when judging the merits of pragmatic encroachment against its competitors. ${ }^{10}$

\footnotetext{
10 A referee suggests that the virtue-based approach makes no such predictions. For, the agent in such cases would have to also consider that by boarding it he or she would be a certain kind of person, one who takes problematic risks. If this referee is right, then we would expect practical deliberation to issue in conclusions like this in cases like the high stakes train case:
}

Yes, all would go well for my career if I boarded, but I don't want to be the kind of person who boards in cases like this, and so I will not board.

Let's set aside the point that it is far from clear that by one's choice of action in a case like this one would become a different kind of person. Consider the above conclusion. I agree it is not absurd. However, I at 


\section{Give up KR?}

All this might make one suspect we ought to give up the knowledge-reasons link after all, despite its initial plausibility. However, it's worth finishing up by going over why this is not so easily done.

How to give up KR? It is very implausible to think that worldly facts about trains, banks, and airports, cannot ever be reasons we have to do things. So, I take it that in the relevant low stakes cases, it's a local train, the bank is open tomorrow, and the plane stops in Chicago are reasons we have to act. And if they are reasons we have to act, they are sufficiently warranted to be such reasons. What should we say happens in the high stakes cases, if we give up KR? In these cases, knowledge is held to remain in place but what is known is claimed to not to be warranted enough to be a reason the person has to act. But notice that this is exactly what a canceler does. Giving up KR, then, requires one to view the relevant defeat as cancelation.

To see the implausibility of this account, let's compare a clear case of cancelation with the alleged cancellation in the high stakes case. Compare:

Yes, the train is a local and it will get me to my destination without a fuss. Still, due to the high stakes and chance it isn't a local, the fact that it is a local is not a reason I have to take it.

with a case of clear cancelation:

Yes, I promised to return the CD to her. But due to the fact that she's released me from that promise, the fact I promised is not a reason I have to return it.

The latter case is unproblematic and positively reasonable. The former is not. Other features of cancelers are also absent: notably, there seems to be a cause for regret in the first case if you do not board the train without double checking but no cause for regret in the second case if you hold onto the CD.

\section{Conclusion}

We haven't found a convincing way of accepting the attractive principle that if you know something then it is warranted enough to be among your reasons for action (i.e., $\mathrm{KR}$ ), while at the same time avoiding pragmatic encroachment. We haven't found a defeater that enables us to see how KR could be true while KJ is false, and we've seen that neither an exclusionary reasons account nor a virtue-theoretic account modeled after Lasonen-Aarnio's work on unreasonable knowledge will allow us to accept KJ while unproblematically rejecting pragmatic encroachment.

It is a familiar point in the literature on knowledge attributions that no theory avoids all problematic consequences. I agree that pragmatic encroachment has problematic consequences. What I hope to have shown here is, if you pardon the pun, that if you get

Footnote 10 continued

least find it alien. What I care about in a case in which my career is on the line is what the results will be for my career, not what kind of person I will be because of my decision. If I can load into my reasoning the train is a local and so will get me to my desired destination, the other considerations just seem to fall away. 
on the train by accepting knowledge-reason links then you will have a difficult time getting off the train before it pulls into pragmatic encroachment station. And there are good reasons for getting on the train. The knowledge-reason principle KR is not only plausible on its face; rejecting it is something we cannot easily abide, as it seems to require us to see facts about serious risk that not-p as cancelers of $\mathrm{p}$ as a reason to do an act, whereas such facts do not seem to behave as cancelers do. ${ }^{11}$

Open Access This article is distributed under the terms of the Creative Commons Attribution 4.0 International License (http://creativecommons.org/licenses/by/4.0/), which permits unrestricted use, distribution, and reproduction in any medium, provided you give appropriate credit to the original author(s) and the source, provide a link to the Creative Commons license, and indicate if changes were made.

\section{References}

Anderson, C. (2015). On the intimate relationship between knowledge and action. Episteme, 12(3), 343-353. Cohen, S. (2012). Does practical rationality constrain epistemic rationality? Philosophy and Phenomenological Research, 85(2), 447-455.

Dancy, J. (2004). Ethics without principles. Oxford: Oxford University Press.

Fantl, J., \& McGrath, M. (2002). Evidence, pragmatics and justification. The Philosophical Review, 111, 67-94.

Fantl, J., \& McGrath, M. (2009). Knowledge in an uncertain world. Oxford: Oxford University Press.

Fantl, J., \& McGrath, M. (2012). Reply to critics. Philosophy and Phenomenological Research, 85(2).

Hawthorne, J. (2004). Knowledge and lotteries. Oxford: Oxford University Press.

Lasonen-Aarnio, M. (2010). Unreasonable knowledge. Philosophical Perspectives, 24(1), 1-21.

Raz, J. (1999). Practical reasons and norms. Oxford: Oxford Clarendon Press.

Stanley, J. (2005). Knowledge and practical interests. Oxford: Oxford University Press.

Weatherson, B. (2011). Defending interest-relative invariantism. Logos and Episteme, 2, 591-609.

Weatherson, B. (2012). Knowledge, bets and interests. In J. Brown \& M. Gerken (Eds.), Knowledge ascriptions (pp. 75-103). Oxford: Oxford University Press.

11 Thanks go to three referees who offered valuable and challenging feedback on an earlier version of the paper. I am also grateful to members of an audience at the University of St. Andrews conference on Normative Reasons. 